\title{
Broadband Four-Fed Circularly Polarized Quadrupole Antenna
}

\author{
Evgeniy R. Gafarov, Alexey A. Erokhin, Yuri P. Salomatov, Member, IEEE \\ Institute of Engineering Physics and Radio Electronics \\ Siberian Federal University \\ Krasnoyarsk, Russia \\ slazen@mail.ru
}

\begin{abstract}
The simulation and experimental results of quadrupole antenna with four power points to create a righthand circular polarization with respect to the systems IRNSS / GLONASS / GPS were presented.
\end{abstract}

\section{INTRODUCTION}

Antennas for global navigation satellite systems (IRNSS/GLONASS/GPS et al.) have different configurations depending on the functional purpose. The antenna is based on a single radiation element despite the field of application (high-precision or interference-proof antenna system et al.). The characteristics of antenna element should be consistent with the requirements of satellite radio navigation systems (SRNS). Existing antenna elements with right circular polarization as in a single realization well as included in the antenna system have different constructions [1]. By designtechnological features there are printing (single-layer, multilayer), spiral, slot antennas and others. [2]. According to a frequency band there are broadband and resonant antenna elements [3]. Printed resonant patch antenna by a multilayer implementation can operate in three frequency bands of the SRNS L1, L2, L3. Such antennas have a good matching and radiation pattern with a level at slide angle $\left(90^{\circ}\right)$ less than -17 $\mathrm{dB}$ [4]. However, there is a degradation of antenna axial ratio (AR) at low elevation angles. The advantage of spiral antenna in printing design is broadband implementation, but disadvantage is the complexity of the feeding power to the antenna. Moreover, the spiral antenna is characterized by a high input impedance. To solve this problem it is necessary to install additional resistance transformer. Furthermore, for use the spiral antenna in the SRNS is necessary to form radiation pattern (RP) of hemispherical shape, but the implementation of a spiral antenna on the ground plane reduces bandwidth. It is possible to use a single-layer resonant patch antenna. Multifrequency mode is achieved by cutting in a radiating element additional slots of different electrical length and other parasitic elements. In spite of the small dimensions the single-layer patch antenna has worse matching properties than multi-layer patch antenna. Also in satellite navigation systems the spiral slotted antenna is used [5]. Such antennas operate at all navigation bands of frequencies and it have low efficiency.

The presented antennas for satellite navigation have following disadvantages: the complexity of the design

The reported study was funded by RFBR and Government of Krasnoyarsk Territory according to the research project № $16-47-243016$ implementation; the worst radiation pattern and match characteristic; narrow bandwidth.

All antenna disadvantages described above can be mitigated in a quadrupole antenna with four fed points. Such antenna has high level of AR at operating angles [6]. The right-hand circular polarization in the quadrupole antennas is achieved by means of additional power dividing bridge with a delay in phase between the radiators. In conformal approach implementation the quadrupole antenna is characterized by a wide radiation pattern $\left(130^{\circ}\right.$ at $\left.-3 \mathrm{~dB}\right)$ with the gain at slide angles approximately $-4 \ldots-6 \mathrm{~dB}$. The antenna system based on quadrupole antenna will receive signals from most areas of the upper hemisphere. One disadvantage of quadrupole antenna is the complexity of feeding power to the radiating elements. But in this article the broadband monopoles rather than not classic bowtie radiator will be resented.

\section{ANTENNA CONFIGURATION}

The antenna consists of broadband divider and radiating elements designed for a frequency range $1.15-1.65 \mathrm{GHz}$ (figure 3).

The power divider was implemented by microstrip technology. The divider provides equal amplitude division of power between the four radiating monopolies [7]. The phases at outputs of divider are $0^{\circ}, 90^{\circ}, 180^{\circ}, 270^{\circ}$ in the entire operating frequency band. The real value of phases at outputs of the divider at range of frequencies is shown in figure 2 . The figure shows that the phase difference in the operating frequency band less than $15^{\circ}$. If to use a divider composed of delay lines, then the value of phase difference at output of the divider may be $50^{\circ}$ or more. Such a value of phase would not be possible to obtain the high quality right-hand circular polarization. The amplitudes of the divider outputs are shown in figure 1. The amplitudes difference is not greater than $0.3 \ldots 0.4 \mathrm{~dB}$ at the operating frequency band. These values do not effect on the amplitude pattern of the radiating system. 


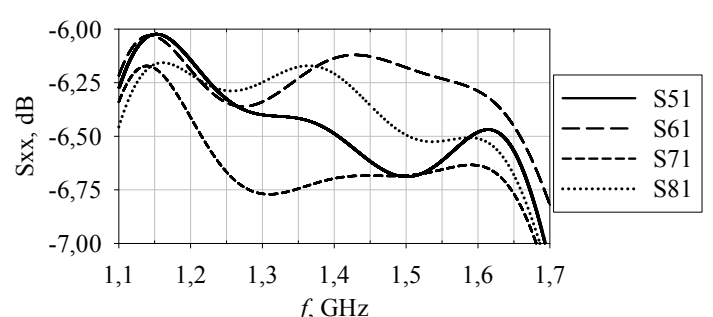

Figure 1. Amplitudes of divider

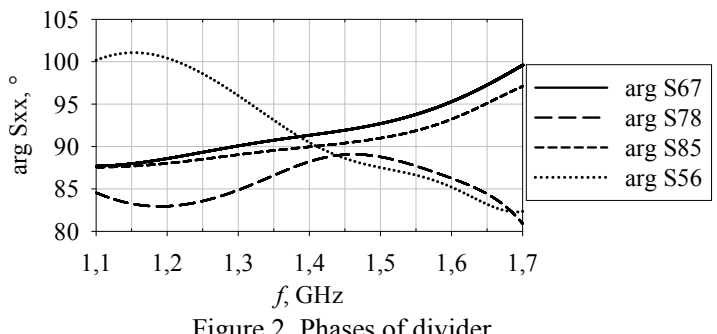

In order to reduce size of antenna the two-layer substrate Rogers RO 4003 of divider was implemented. The lower layer of the substrate is a divider with outputs $0^{\circ}$ and $180^{\circ}$. The upper layer is the two dividers with outputs $0^{\circ}$ and $90^{\circ}$. Microwave transition between layers of divider was realized by means of screws with a diameter of $2.5 \mathrm{~mm}$. The divider circuit includes segments on the basis of Wilkinson in order to isolate three power divider components.

Radiated monopoles are located above the substrate. Mounting to the substrate and transfer the microwave power to monopolies is carried out by means of screws $2.5 \mathrm{~mm}$ (fig. 3 ). The screws also serve to combine two layers of substrates together. The ground plane of two dividers and quadrupoles is the general. The radiating elements were implemented of galvanized steel of $0.5 \mathrm{~mm}$ thick.
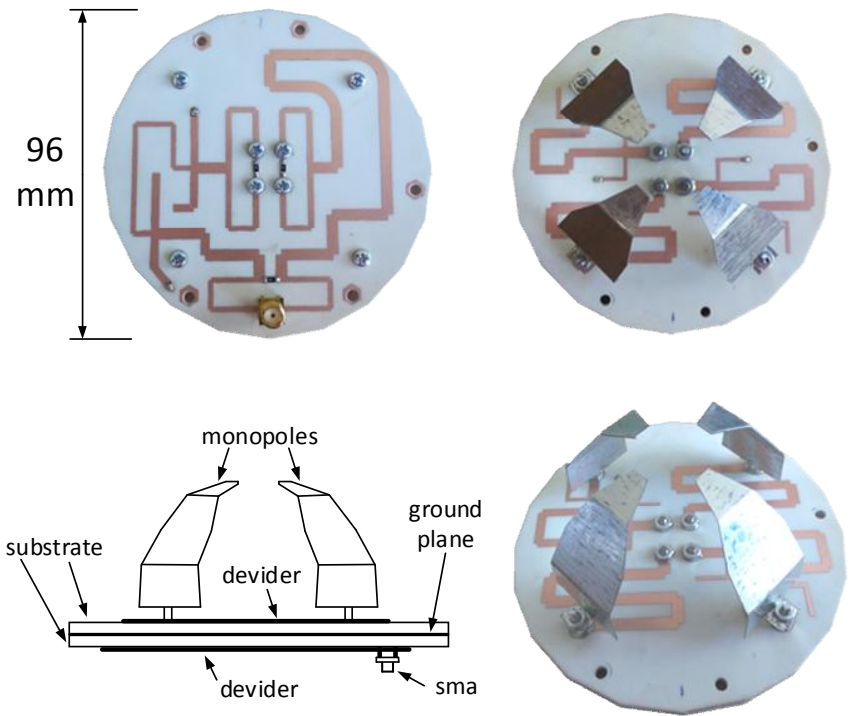

Figure 3. Photo and design of quadrupole antenna
The distance between the lower edge of the monopoly and the screen is $5 \mathrm{~mm}$. The height of the monopole corresponds to a quarter wavelengths. The common dimensions of the antenna are $96 \times 96 \times 45 \mathrm{~mm}$.

To connect with feeding network on the bottom side of substrate the SMA connector is located. In general, the antenna structure is a very tough by means of screws and radiating elements. In other words, the antenna may be used in adverse environmental conditions.

The antenna has a small transverse dimension of the order half wavelength [8]. This fact allows use in antenna arrays, as well as in places with the limited size of the antenna-feeder path.

\section{FIELD ANALYSIS}

The electromagnetic modeling of quadrupole antenna in CAD and then breadboarding were implemented. The experimental investigation was carried out in an anechoic chamber to minimize the reflected signal. Measurements of the antenna fields at the far field in the system of biorthogonal oscillations were produced [9]. Further, according to experimental measurements the radiation patterns and axial ratio were calculated. The antenna characteristics are presented below.
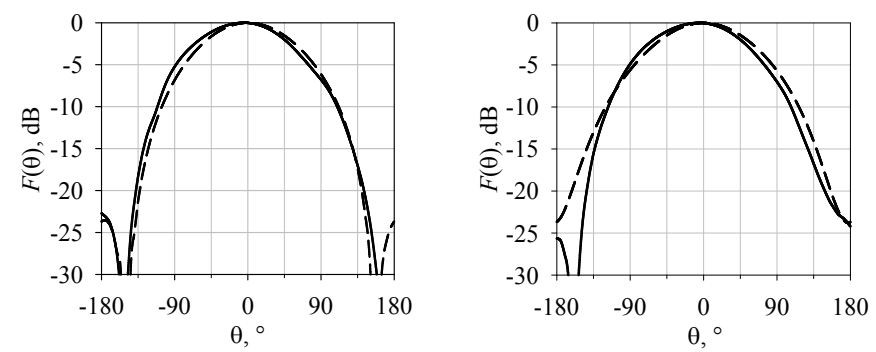

Figure 4. Radiation pattern at $1.175 \mathrm{GHz}$, solid line - experiment; dashed line - modeling
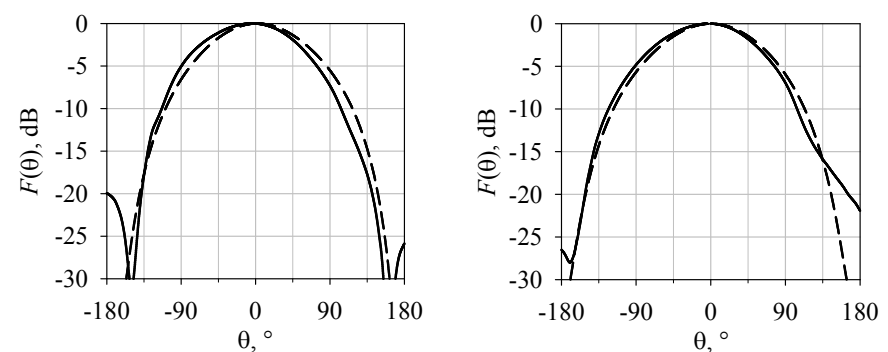

Figure 5. Radiation pattern at $1.25 \mathrm{GHz}$, solid line - experiment; dashed line - modeling
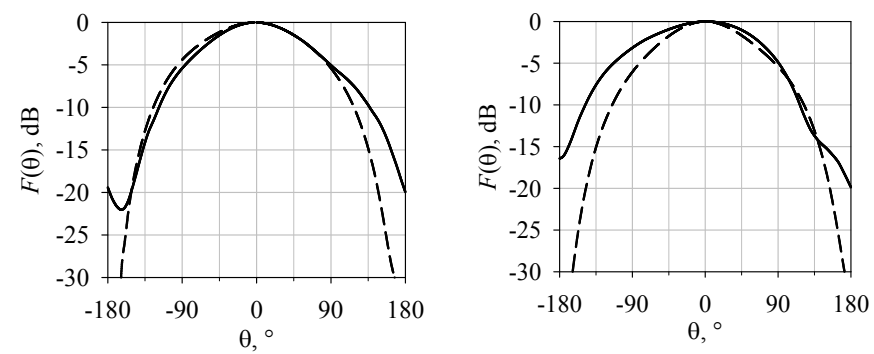

Figure 6. Radiation pattern at $1.6 \mathrm{GHz}$, solid line - experiment; dashed line - modeling 

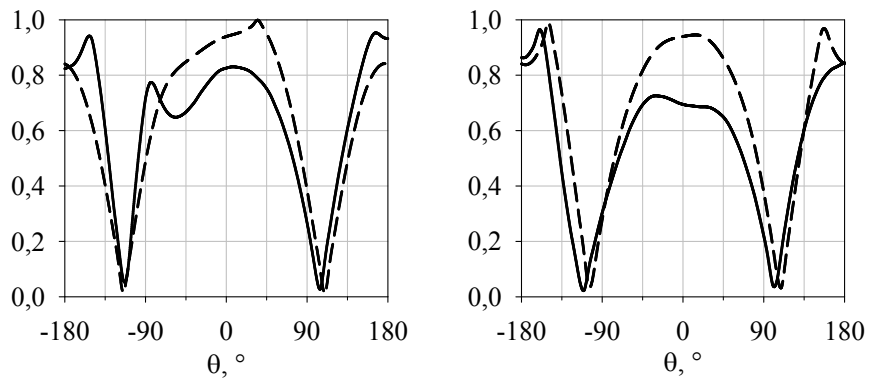

Figure 7. Axial ratio at $1.175 \mathrm{GHz}$, solid line - experiment; dashed line modeling
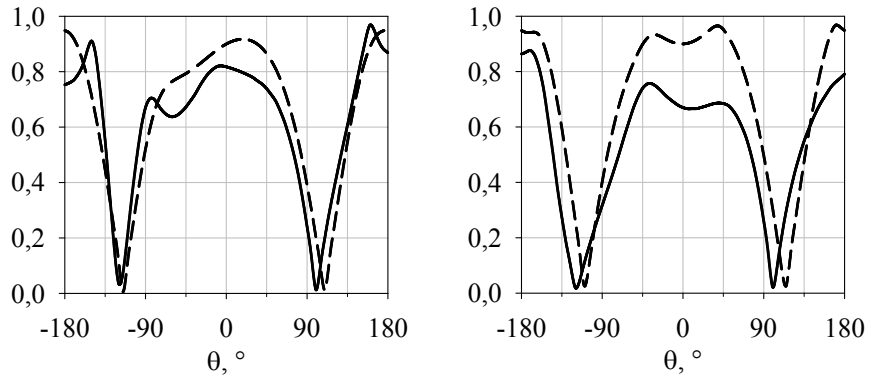

Figure 8. Axial ratio at $1.25 \mathrm{GHz}$, solid line - experiment; dashed line modeling
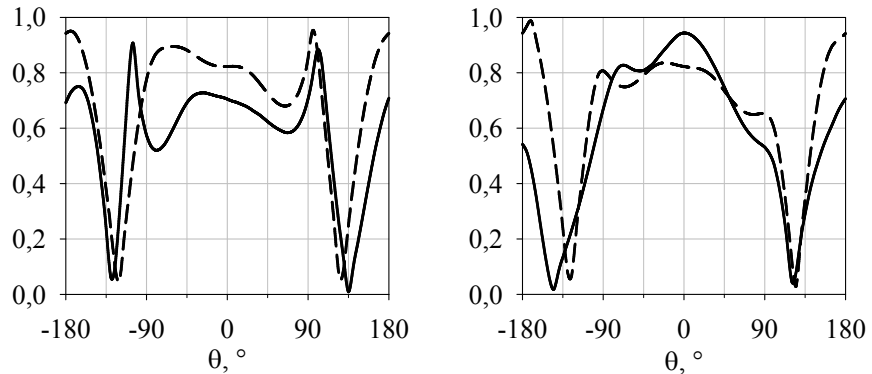

Figure 9. Axial ratio at $1.6 \mathrm{GHz}$, solid line - experiment; dashed line modeling

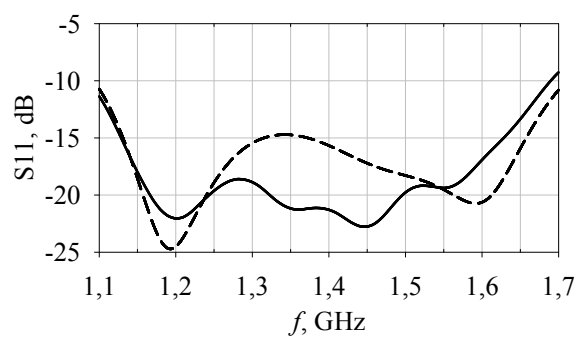

Figure 10. Reflection coefficient S11, solid line - experiment; dashed line - modeling

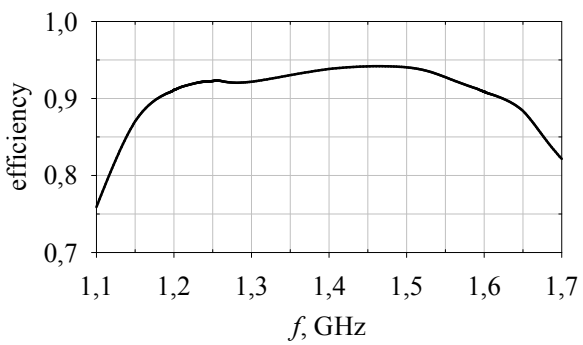

Figure 11. Efficiency of quadrupole antenna
There is a good convergence of calculated and experimental results. AR of antenna in the whole upper hemisphere has a high value, in the reference direction it is more than 0.7 . At slide angles $\left( \pm 90^{\circ}\right)$ AR is reduced up to values of $0.4-0.5$ based on the experimental results (figures 7-9). Radiation pattern for the L2 and L3 frequency has a good agreement with the simulation results (figures 4-5). Taking into account the direct loss and return loss of antenna the efficiency is $90 \%$ or more for the frequencies of satellite navigation (figure 11). Directivity of antenna is $3.5-4 \mathrm{~dB}$.

\section{CONCLUSIONS}

The quadrupole antenna for satellite radio navigation applications has been investigated and developed. Unlike many existing designs of antennas, the new antenna is characterized by the best characteristics for receiving satellite navigation signals. In more details, a high AR in the whole upper hemisphere. Wide amplitude radiation pattern to provide the gain $-4 \ldots-6 \mathrm{~dB}$ at sliding angles. The efficiency is high at operating frequency bands.

Also it should be noted that the antenna has a tough structure by screws. The screws serve to transmit microwave power to the radiators and for mounting simultaneously.

Using of quadrupole antenna in the field of satellite radio navigation system will improve the quality of the received signal by means of elimination the interference component (multipath) and thereby to increase the accuracy of positioning.

In the field of anti-jamming satellite navigation systems due to small dimensions the antenna can be used as part of a digital array to remove active jamming. In addition to the above, due to the spatial filtering in the antenna, the increased useful power above the interference signal component is obtained.

\section{REFERENCES}

[1] Y. Zhou, Ch. Ch. Chen, J. L. Volakis. Single-fed Circularly Polarized Antenna Element With Reduced Coupling for GPS Arrays - IEEE Transactions On Antennas And Propagation, vol. 56, No. 5, May 2008.

[2] L. I. Basilio, R. L. Chen, J. T. Williams, David R. Jackson. A New Planar Dual-Band GPS Antenna Designed for Reduced Susceptibility to Low-Angle Multipath. IEEE Transactions on Antennas and Propagation, Vol. 55 , No. 8 .

[3] E. R. Gafarov; Y. P. Salomatov, «Hexagonal FSS for GLONASS/GPS antenna with improved axial ratio», IEEE Control and Communications (SIBCON), 2011 International Siberian Conference, Krasnoyarsk, Russia, 15-16 Sept. 2011, pp. $159-161$.

[4] Gafarov E. R., Salomatov Y. P, «The dual-band antenna for navigation satellite systems», IEEE Microwave \& Telecommunication Technology (CriMiCo), 2014 24th International Crimean Conference, Sevastopol, 713 Sept. 2015.

[5] E. R. Gafarov; Y. P. Salomatov, «The spiral slot antenna with a horizontal choke ring», IEEE Microwave \& Telecommunication Technology (CriMiCo), 2014 24th International Crimean Conference, Sevastopol, 7-13 Sept. 2014, pp. $513-514$.

[6] A. V. Stankovsky; S. V. Polenga; A. D. Nemshon; Y. A. Litinskaya; E. R. Gafarov; Yu. P. Salomatov, «Meander-line polarizer for omnidirectional antenna», IEEE 2016 International Siberian Conference on Control and Communications (SIBCON), Moscow, Russia, 12-14 May 2016, pp. 1 - 4 
[7] E. R. Gafarov; A. V. Stankovsky, Y. P. Salomatov, «A GNSS quadrupole antenna with a spatial polarizer for the suppression of lowangle multipath», IEEE 2016 International Siberian Conference on Control and Communications (SIBCON), Moscow, Russia, 12-14 May 2016, pp. $1-4$

[8] J. G. Maloney, B. N. Baker, J. J. Acree, J. W. Schultz, J. A. Little, D. D Reuster. Fragmented Aperture Antenna Design of Miniaturized GPS CRPA: Model and Measurements - IEEE Transactions On Antennas and Propagation, vol. 55, No. 4, April 2007.

[9] K. V. Lemberg, Y. P. Salomatov, E. R. Gafarov, «GNSS antenna characteristics using bi-orthogonal far-field measurement», IEEE Microwave \& Telecommunication Technology (CriMiCo), 24th International Crimean Conference, Sevastopol, 7-13 Sept. 2014, pp. 932 -933 . 